Check for updates

Cite this: RSC Adv., 2019, 9, 38469

\title{
Selective sensing and visualization of pesticides by ABW-type metal-organic framework based luminescent sensors $\dagger$
}

\author{
Ling Di, (D) ${ }^{a}$ Zhengqiang Xia, ${ }^{b}$ Jian Li, ${ }^{a}$ Zhongxing Geng, ${ }^{a}$ Chun Li, ${ }^{a}$ Yang Xing (DD *a \\ and Zhanxu Yang*a
}

A new ABW-type luminescent metal-organic framework (MOF) namely $\left(\mathrm{H}_{3} \mathrm{O}\right)\left[\mathrm{Zn}_{2} \mathrm{~L}\left(\mathrm{H}_{2} \mathrm{O}\right)\right] \cdot 3 \mathrm{NMP} \cdot 6 \mathrm{H}_{2} \mathrm{O}(1)$, constructed with eco-friendly $\mathrm{Zn}^{2+}$ and the multicarboxylate intraligand $\left(\mathrm{LH}_{5}\right)$ was designed, synthesized and fully characterized by $\mathrm{X}$-ray single-crystal diffraction, steady-state absorption and emission spectroscopy, and SEM observations. The MOF-based suspension sensor 1 (NMP) demonstrated high sensitivity to low-concentration pesticides of chlorothalonil (CTL), nitrofen (NF), trifluralin (TFL), and 2,6dichloro-4-nitroaniline (DCN), which was assigned to the synergistic effect of the photoinduced electron transfer and the fluorescence resonance energy transfer. With the highest luminescent detection efficiency ( $K_{\mathrm{Sv}}$ up to $11.194 \mu \mathrm{mol}^{-1}$ and LOD down to $2.93 \mathrm{ppm}$ ) to DCN, 1 (NMP) was successfully applied for the selective sensing of DCN. The MOF-based film sensor 1 (film) illustrated the selective visualization sensing of trace amounts of DCN. In addition, based on the high saturated vapor pressure of TFL and the unique bathochromic shift effect to the emission maxima of 1 , the MOF-based luminescent vapor sensing device 1 (LED) successfully exhibited operability for sensing of TFL vapor. The results illustrated a feasible approach to construct new MOF-based luminescent sensors for selective sensing and visualization of pesticides.

Received 30th October 2019

Accepted 18th November 2019

DOI: $10.1039 / c 9 r a 08940 c$

rsc.li/rsc-advances

\section{Introduction}

The extensive utilization of pesticides plays a pivotal role in agriculture productivity. ${ }^{1,2}$ However, pesticide residues lead to harmful impacts on human health (e.g., eye and skin irritation, headache, cancer, and asthma, etc.)..3 In developing countries, environmental pollution and the associated health risks have already resulted in approximately $20 \%$ of the total disease load. ${ }^{1}$ Swift and reliable detection of pesticides has become one of the research topics of importance concerning human health, public security, and environmental protection., ${ }^{5,6}$ Conventional methods of pesticide detection (e.g., capillary electrophoresis, ${ }^{7,8}$ gas chromatography ${ }^{9,10}$ and flow injection spectrophotometric analysis, ${ }^{11}$ etc.) have often been restricted by shortcomings such as high costs of analysis, and the need for sophisticated instrumentation and time-consuming pretreatment. ${ }^{12}$ In

${ }^{a}$ College of Chemistry, Chemical Engineering and Environmental Engineering, Liaoning Shihua University, Fushun 113001, China. E-mail: xingyang@lnpu.edu.cn; yangzhanxu@lnpu.edu.cn

${ }^{b}$ Key Laboratory of Synthetic and Natural Functional Molecule Chemistry of Ministry of Education, College of Chemistry and Materials Science, Northwest University, Xi'an 710127, China

$\dagger$ Electronic supplementary information (ESI) available: Crystal data, TGA curve, photographs of fluorescence response, fitting formula and data. CCDC 1554378. For ESI and crystallographic data in CIF or other electronic format see DOI: $10.1039 / \mathrm{c} 9 \mathrm{ra} 08940 \mathrm{c}$ consideration of restrictions associated with aforementioned detection methods, luminescent detection and sensing of pesticides has attracted widespread attention because of merits of quick response, high sensitivity, simplicity, convenient to carry, and perfect reliability. ${ }^{13,14}$

Metal-organic frameworks (MOFs) have attracted particular concern in research fields of biomedicine, ${ }^{15-17}$ chemical sensing, ${ }^{18-22}$ and light-emitting devices. ${ }^{23,24}$ Luminescent MOFs are effective sensing platforms of pesticides due to advantages of variety porosity, intense emission of fluorescence, high specific surface area, tunability of structures, and chemical properties. ${ }^{25,26}$ The porous internal structures of luminescent MOFs were frequently leading to preconcentration of analytes that giving lower detection limits and high-efficiency sensing. ${ }^{27,28}$ The changes of sensing signals in luminescence intensity is closely related to the electron density and the ability of MOFs to donate electrons. ${ }^{29,30}$ Because of photoluminescence properties of intraligands with the $\pi$-conjugated aromatic system, frontier molecular orbitals of luminescent MOFs are sensitive to interrupt by analytes. ${ }^{31-33}$

Pesticides chlorothalonil (CTL), ${ }^{34,35}$ nitrofen (NF), ${ }^{36}$ and trifluralin (TFL) ${ }^{37,38}$ (Fig. S1, ESI $\dagger$ ) had been decided to be carcinogens. And 2,6-dichloro-4-nitroaniline (DCN) (Fig. S1, ESI†) belongs to toxicity class IV, which is assigning to a suspected carcinogen. ${ }^{39,40}$ Here in, a new $\mathrm{Zn}^{2+}$ based luminescent MOF (1) with a formula of $\left(\mathrm{H}_{3} \mathrm{O}\right)\left[\mathrm{Zn}_{2} \mathrm{~L}\left(\mathrm{H}_{2} \mathrm{O}\right)\right] \cdot 3 \mathrm{NMP} \cdot 6 \mathrm{H}_{2} \mathrm{O}$ was 
constructed by the hydrothermal synthesis method with multicarboxylate ligand $\mathrm{LH}_{5}=2,5$-(6-(4-carboxyphenylamino)-1,3,5triazine-2,4-diyldiimino)diterephthalic acid (Fig. S1, ESI $\dagger$ ) and zinc nitrate. Systematic research with 1 as a luminescent sensor on low-concentration detection of pesticides CTL, NF, TFL, and DCN was reported. Based on the hypersensitivity of 1 to DCN with LOD down to $2.93 \mathrm{ppm}$, a selective visualization sensing of DCN was demonstrated. In addition, a MOF-based luminescent vapor sensing device $\mathbf{1}$ (LED) was constructed for naked-eye sensing of TFL vapor.

\section{Experimental}

\section{Materials and physical measurements}

Without further purification, all the commercially available reagents were used. The Nicolet-20DXB spectrometer was applied for the record of IR spectra (400-4000 $\mathrm{cm}^{-1}$ with $\mathrm{KBr}$ pellets). The Vario EL elemental analyzer was used for the measurement of elemental analyses (C, H, N). A TA-Q600 thermogravimetric analyzer was applied to perform thermogravimetric analyses (TGA) with nitrogen atmosphere of 100 $\mathrm{mL} \min ^{-1}$ and the heating rate of $5{ }^{\circ} \mathrm{C} \min ^{-1}$. The Bruker D8 Advance diffractometer ( $\mathrm{Cu} \mathrm{K} \alpha$ radiation with $\lambda$ of $1.5418 \AA$, and a scan speed of 0.1 degree per second) was used to collect the powder X-ray diffraction (PXRD) data over $3^{\circ}$ to $50^{\circ}$ of the $2 \theta$ range at room temperature. An LCQ-TOF Micro MS mass spectrometer recorded high-resolution MS (EI). The Agilent G9800A luminescence spectrophotometer was applied to measure the emission spectra at room temperature. Moreover, UV/Vis absorption spectra were recorded by an Agilent $5000 \mathrm{UV} /$ Vis/NIR spectrophotometer. A Malvern Nano-ZS90 Zetasizer was applied to measure the particle size distribution of suspension sensor 1 (NMP). The quantum yield of the suspension sensor 1 (NMP) was measured with $\operatorname{Ir}(\mathrm{ppy})_{3}$ (quantum yield of 0.40 ) as a standard. ${ }^{41,42}$ And the solid-state quantum yields of 1 (original), and 1 (ground) were measured on a HITACHI F-7000 spectrophotometer by employing an integrating sphere.

\section{Synthesis procedure}

According to the method in literature, ${ }^{32}$ intraligand $\mathrm{LH}_{5}$ was synthesized and fully characterized by high-resolution MS. HRMS (EI) for $\mathrm{LH}_{5}$, calc.: 573.1006 [M-H]. Found: 573.1008 [M$\mathrm{H}] \quad$ (Fig. S2, ESI $\dagger$ ). $\left(\mathrm{H}_{3} \mathrm{O}\right)\left[\mathrm{Zn}_{2} \mathrm{~L}\left(\mathrm{H}_{2} \mathrm{O}\right)\right] \cdot 3 \mathrm{NMP} \cdot 6 \mathrm{H}_{2} \mathrm{O} \quad$ (1). $0.02 \mathrm{mmol}(5.9 \mathrm{mg}) \mathrm{Zn}\left(\mathrm{NO}_{3}\right)_{2} \cdot 6 \mathrm{H}_{2} \mathrm{O}$ and $0.02 \mathrm{mmol}(11.5 \mathrm{mg})$ multicarboxylate ligand $\mathrm{LH}_{5}$ were dissolved in $2.0 \mathrm{~mL} \mathrm{NMP} \mathrm{in}$ a vessel, to which $0.5 \mathrm{~mL}$ deionized water was added. Heating the hermetic vessel at $115{ }^{\circ} \mathrm{C}$ for 24 hours. Subsequently, the mixture cooled to $25{ }^{\circ} \mathrm{C}$ with a rate of $5{ }^{\circ} \mathrm{C}$ per hour. The transparent polygonal crystals of 1 were obtained and washed with NMP and air-dried for 24 hours. Yield: 61.3\%. Element analysis (\%): calc. for $\mathrm{C}_{41} \mathrm{H}_{56} \mathrm{~N}_{9} \mathrm{O}_{21} \mathrm{Zn}_{2}$ : C (43.13), $\mathrm{H}(4.94), \mathrm{N}$ (11.04); found: $\mathrm{C}$ (43.41), $\mathrm{H}$ (4.26), $\mathrm{N}$ (11.13). Selected IR $\left(\mathrm{cm}^{-1}\right)$ : 3269, 3131, 1638, 1571, 1499, 1412, 1347, 791, 769 (Fig. S3, ESI $\dagger$ ).

\section{Detection of pesticides with suspension sensor}

The 1 (original) was obtained by desiccating fresh synthesized 1 in a vacuum dryer for 1 hour at $60{ }^{\circ} \mathrm{C}$. Before the sensing experiments of pesticide, $\mathbf{1}$ (original) was ground to a fine powder which was named $\mathbf{1}$ (ground). And then $\mathbf{1}$ (ground) was dispersed in NMP $\left(1.0 \mathrm{mg} \mathrm{mL}^{-1}\right)$ with ultrasonic treatment for 5 hours. Whereafter, steady suspension sensor 1 (NMP) was formed through 24 hours of aging treatment. The pesticides (CTL, NF, TFL, and DCN) were configured to solutions (0.1 $\left.\mathrm{mol} \mathrm{L}^{-1}\right)$ with NMP, respectively.

The concentration-dependence of luminescent quenching responses of 1 (NMP) were carried out by incremental addition of pesticides solution into 1 (NMP), respectively. The steadystate emission spectra of the resulting mixtures were obtained. The equation of $\left[\left(I_{0}-I\right) / I_{0}\right] \times 100 \%$ was employed for the luminescent quenching efficiency (QE) of $\mathbf{1}$ (NMP) for each pesticide. Sensing experiments of pesticides were carried out three times parallelly demonstrating congruity of results.

\section{Construction procedure of the luminescent vapor sensing device}

Ethyl cellulose (EC, $10.0 \mathrm{mg}$ ) were dissolved in $\mathrm{CH}_{2} \mathrm{Cl}_{2}(0.5 \mathrm{~mL})$, and then 1 (ground) $\left(5.0 \mathrm{mg}\right.$ ) was dispersed in the $\mathrm{EC} / \mathrm{CH}_{2} \mathrm{Cl}_{2}$ solution with ultrasonic treatment for 10 minutes to form a steady suspension. A commercially available ultraviolet LED (Fig. 12A) was soaked into the suspension for 1 minute. And then the LED was removed and dried for 5 minutes. Repeating the soaking operation 5 times, a luminescent vapor sensing device 1 (LED) (Fig. 12B) was constructed. 1 (LED) was dried for 12 hours to remove $\mathrm{CH}_{2} \mathrm{Cl}_{2}$ before the vapor sensing experiment.

\section{Results and discussion}

\section{Crystal structure}

The significant structure refinement data of $\mathbf{1}$ was shown in Table 1 and selected bond lengths $(\AA)$ and angles $\left(^{\circ}\right)$ of 1 was exhibited in Table S1 (ESI $\dagger$ ). Single crystal of 1 crystallized in the space group of $P 2_{1} 2_{1} 2_{1}$ with a 4 -connected $3 \mathrm{D}$ positive framework. The negative charge of the framework was balanced with $\mathrm{H}_{3} \mathrm{O}^{+}$formed from crystal water. Two isolated $\mathrm{Zn}^{2+}$ (Zn1 and $\mathrm{Zn} 2$ ) and an isolated multicarboxylate ligand were illustrated in the asymmetric unit. The distorted tetrahedral geometry with four-coordinate was adopted by $\mathrm{Zn} 1$ which was established by a coordinate molecule of $\mathrm{H}_{2} \mathrm{O}$ and five atoms of oxygen which were provided by three multicarboxylate ligands of $\mathrm{LH}_{5}$. While similar distorted tetrahedral geometry was adopted by Zn2 with four atoms of oxygen which were provided by three $\mathrm{LH}_{5}$. Three $\mathrm{LH}_{5}$ were employed to build the bridges between $\mathrm{Zn} 1$ and $\mathrm{Zn} 2$ with the $\mathrm{Zn}-\mathrm{Zn}$ distance of $3.36 \AA$ (Fig. 1A). And five carboxyl moieties of four $\mathrm{LH}_{5}$ were selected to form the 4-connected node based propeller-like $\mathrm{MBB}$ of $\left\{\mathrm{Zn}_{2}\left(\mathrm{CO}_{2}\right)_{5}\right\}$. The $\mathrm{Zn}-\mathrm{O}$ distances were 1.924(4)-2.057(5) $\AA$, and the $\mathrm{O}-\mathrm{Zn}-\mathrm{O}$ bond angles were $83.37(18)^{\circ}-132.30(16)^{\circ}$ which were typical ranges for related carboxylic acid contained MOFs (Fig. 1A). ${ }^{43}$ The $\mu_{7}-$ $\kappa_{\mathrm{O}}^{1}: \kappa_{\mathrm{O}}^{1}: \kappa_{\mathrm{O}}^{2}: \kappa_{\mathrm{O}}^{1}: \kappa_{\mathrm{O}}^{1}: \kappa_{\mathrm{O}}^{1}: \kappa_{\mathrm{O}}^{1}$ coordination mode was adopted by $\mathrm{LH}_{5}$ 
with five multicarboxylate moieties coordinating with seven $\mathrm{Zn}^{2+}$ of four MBBs (Fig. 1B).

Moreover, the MBB of $\left\{\mathrm{Zn}_{2}\left(\mathrm{CO}_{2}\right)_{5}\right\}$ was extended to constitute a $3 \mathrm{D}$ rectangle lattice with the window size of $21.3 \times 13.4 \AA^{2}$ (Fig. 2A). The multicarboxylate ligand of $\mathrm{LH}_{5}$ was deemed as a type of 4-connection. The $3 \mathrm{D}$ anionic framework resulted with the packing of 4-connected MBBs of $\left\{\mathrm{Zn}_{2}\left(\mathrm{CO}_{2}\right)_{5}\right\}$ and 4-connected ligands in the same ratio (Fig. 2B).

4106.4 $\AA^{3}$ out of the $6217.0 \AA^{3}$ in the volume of the unit cell was accessible for solvent molecules. Unordered hydrated cations and NMP were filled in the channels. The analysis of topology by TOPOS illustrated that $\mathbf{1}$ was assigned as an ABW network with 4-connections of zeolitic uninodal and $\left(4^{2}\right)\left(6^{3}\right)(8)$ for Schläfli symbol. The ligand nodes and the MBB demonstrated the same vertex symbols of $4 \cdot 6 \cdot 4 \cdot 6 \cdot 6_{2} \cdot 8_{6}$ (Fig. $2 \mathrm{~B}$ ).

\section{Thermal stability}

The purity and crystallinity of $\mathbf{1}$ were confirmed by PXRD (Fig. S4, ESI $\dagger$ ). Analysis of thermogravimetric (TGA) was applied to study the thermal stability of $\mathbf{1}$. TGA was carried out in 25$850{ }^{\circ} \mathrm{C}$ under dry nitrogen atmosphere. $37.09 \%$ of weight lost from $25{ }^{\circ} \mathrm{C}$ to $239{ }^{\circ} \mathrm{C}$, which corresponded to uncoordinated molecules of $6 \mathrm{H}_{2} \mathrm{O}, 3 \mathrm{NMP}$, and coordinated molecule of $1 \mathrm{H}_{2} \mathrm{O}$ (calc. for $37.07 \%$ ). The speediness of weight loss illustrated the decomposition of 1 beyond $239{ }^{\circ} \mathrm{C}$ (Fig. S5, ESI $\dagger$ ).

\section{Morphology and luminescent property}

As shown in Fig. 3A, the SEM image exhibited the symmetric polygonal structure of $\mathbf{1}$ (original) crystal. The luminescence properties of $\mathrm{LH}_{5}$ and 1 were studied (Fig. 3B, C, and E). 1

Table 1 Crystal data and structure refinement for 1

$\begin{array}{ll}\text { CCDC } 1554378 & \mathbf{1} \\ \text { Formula } & \mathrm{C}_{41} \mathrm{H}_{56} \mathrm{~N}_{9} \mathrm{O}_{21} \mathrm{Zn}_{2} \\ \text { Formula weight } & 1141.69 \\ \text { Crystal system } & \text { Orthorhombic } \\ \text { Space group } & P 2_{1} 2_{1} 2_{1} \\ a(\AA) & 12.717(3) \\ b(\AA) & 16.730(3) \\ c(\AA) & 27.427(6) \\ \alpha\left({ }^{\circ}\right) & 90 \\ \beta\left({ }^{\circ}\right) & 90 \\ \gamma\left({ }^{\circ}\right) & 90 \\ V\left(\AA^{3}\right) / Z & 5835(2) / 4 \\ D_{\text {calcd }}\left(\mathrm{g} \text { cm }^{-3}\right) & 0.930 \\ \mu\left(\mathrm{mm}{ }^{-1}\right) & 0.865 \\ F(000) & 1660 \\ \theta \text { range }\left({ }^{\circ}\right) & 2.50-24.88 \\ \text { Reflections collected/unique } & 18571 / 10006 \\ R(\text { int }) & 0.0526 \\ \text { GOF on } F^{2} & 1.063 \\ R_{1}{ }^{a}, I>2 \sigma(I) \text { (all) } & 0.0667(0.0722) \\ \text { w } R_{2}{ }^{b}, I>2 \sigma(I) \text { (all) } & 0.1860(0.1896) \\ \text { Max/mean shift in final cycle } & 0.001 / 0.000\end{array}$

${ }^{a} R=\sum\left(|| F_{\mathrm{o}}|-| F_{\mathrm{c}}||\right) / \sum\left|F_{\mathrm{o}}\right| \cdot{ }^{b} \mathrm{w} R=\left\{\sum w\left[\left({F_{\mathrm{o}}}^{2}-F_{\mathrm{c}}{ }^{2}\right)\right] / \sum w\left[\left(F_{\mathrm{o}}{ }^{2}\right)^{2}\right]\right\}^{5}, w=$ $\left[\sigma^{2}\left(F_{\mathrm{o}}{ }^{2}\right)+(a P)^{2}+b P\right]^{-1}$, where $P=\left[\left({F_{\mathrm{o}}}^{2}+2{F_{\mathrm{c}}}^{2}\right) / 3\right] . \mathbf{1}, a=0.1429, b=$ 1.8559 .

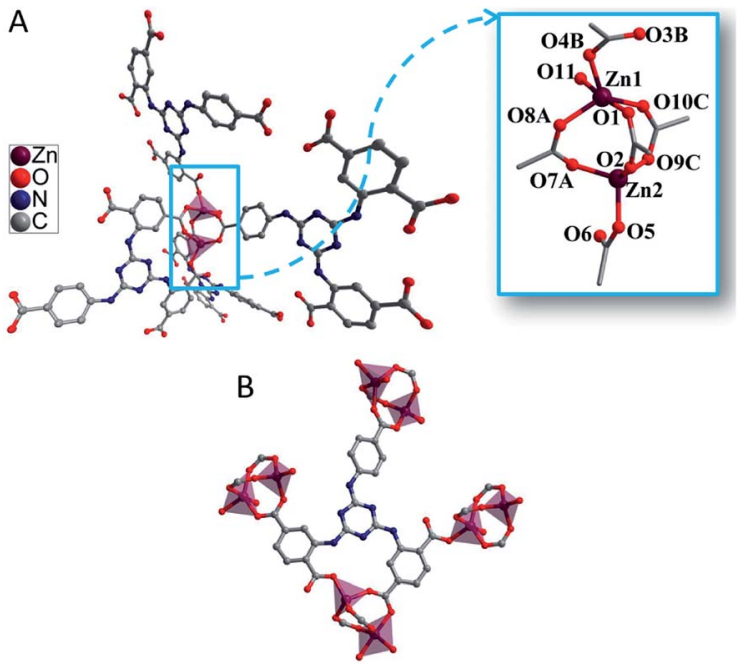

Fig. 1 (A) The coordination environment of the binuclear $\mathrm{Zn}^{2+}$ center of 1 . Symmetry codes: $A=1 / 2+x,-1 / 2-y,-z ; B=1 / 2+x,-3 / 2-y$, $-z ; C=3 / 2-x,-1-y,-1 / 2+z$. (B) The bridging mode of intraligand.

(original) and $\mathbf{1}$ (ground) are faint yellow crystals and milky powder, respectively, under daylight. When being excited with UV light, 1 (original) emitted intense blue-green fluorescence while 1 (ground) showed a few hypsochromic shift of fluorescence which could be distinguished by naked eyes (Fig. 3B). This phenomenon which has been confirmed by the emission spectra (Fig. 3C) and the CIE plots (Fig. 3E) may be caused by the changes of guest molecules in channels of $\mathbf{1}$ during grinding. ${ }^{44,45}$ Under the excitation of $360 \mathrm{~nm}$, the free multicarboxylate ligand $\mathrm{LH}_{5}$ demonstrated intense fluorescence of broad band which attributed to $\pi^{*}-\pi$ or $\pi^{*}-\mathrm{n}$ transitions with
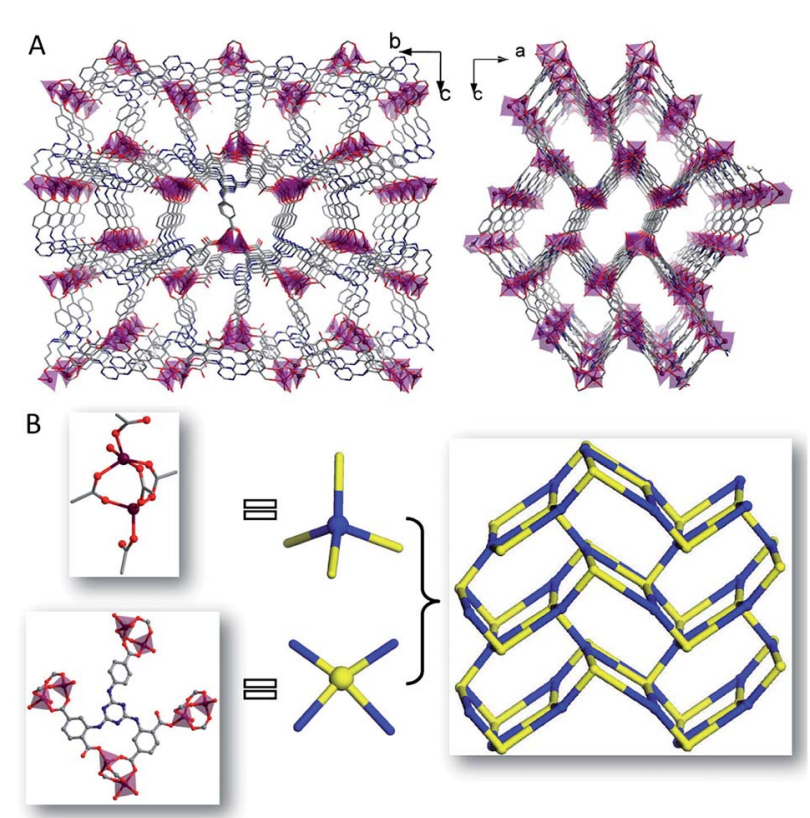

Fig. 2 (A) The 3D frameworks observed along $a$ and $b$ axes. (B) Schematic representation of the 4-connected net in 1 . 

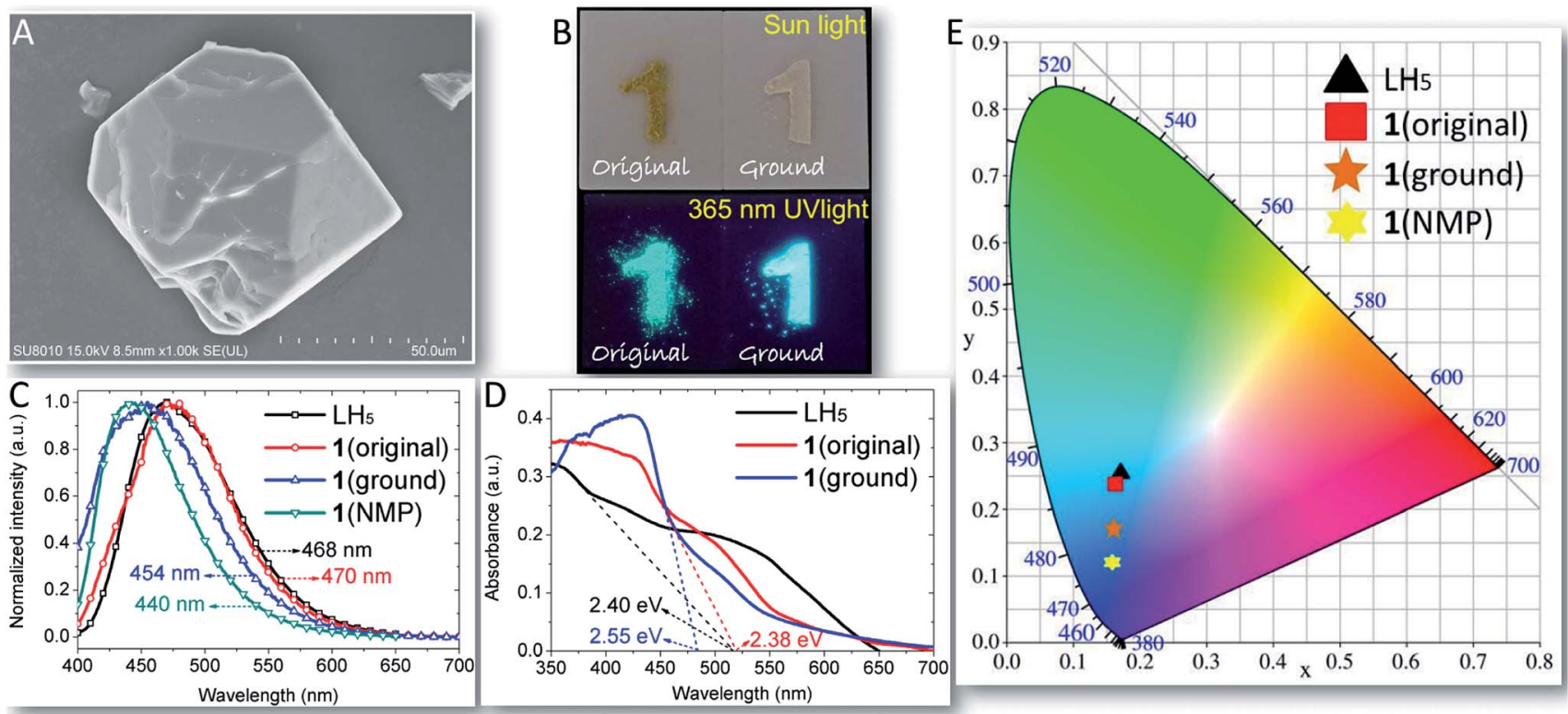

Fig. 3 (A) The SEM image of 1 (original) crystal. (B) The solid-state luminescent photographs of 1 (original) and 1 (ground) under sun light and $365 \mathrm{~nm}$ UV light. (C) Emission spectra of $\mathrm{LH}_{5}, 1$ (original), 1 (ground), and 1 (NMP) ( $\lambda_{\mathrm{ex}}=365 \mathrm{~nm}$ ). (D). UV/Vis diffuse reflect spectra and the band gap energy value $\left(E_{\mathrm{g}}, E_{\mathrm{g}}=1240 / \lambda_{\text {edge }}\right)$ of $\mathrm{LH}_{5}, 1$ (original), and 1 (ground). (E) The CIE plots for $\mathrm{LH}_{5}, 1$ (original), 1 (ground), and 1 (NMP).

emission maxima of $468 \mathrm{~nm} .{ }^{46}$ And the solid-state luminescence of 1 (original) showed a similar emission maximum of $470 \mathrm{~nm}$. In comparison with $\mathbf{1}$ (original), 1 (ground) demonstrated
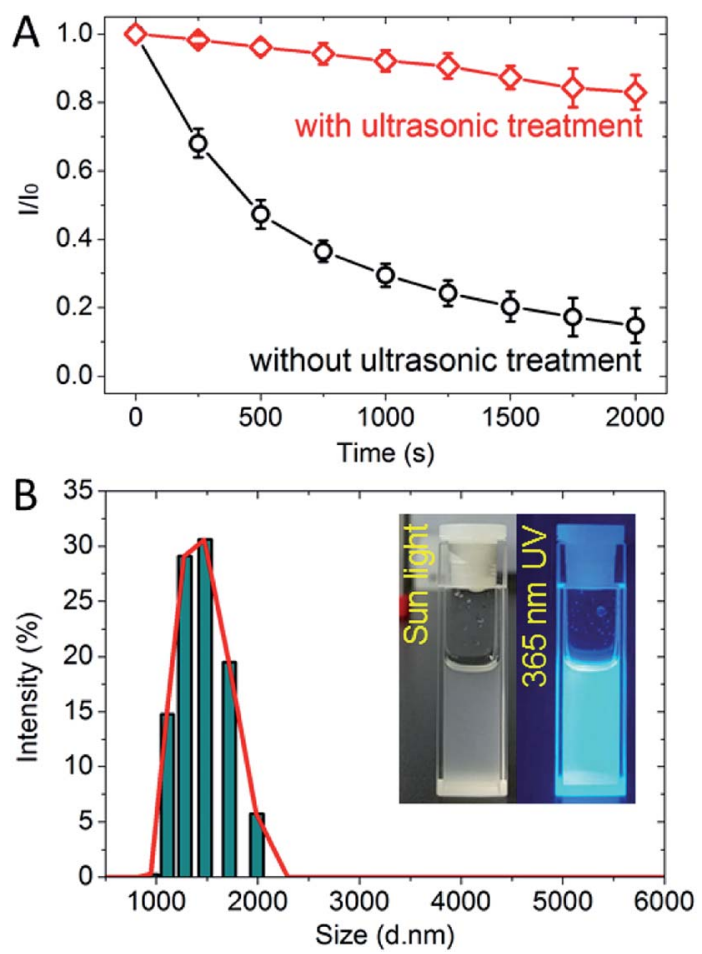

Fig. 4 (A) Fluorescence intensity variation of 1 (NMP) with or without ultrasonic treatment in $2000 \mathrm{~s}$ of stabilization. (B) The particle size distribution of 1 (NMP) (inset: photographs of 1 (NMP) under sunlight/ $365 \mathrm{~nm}$ UV light). hypsochromic emission maxima of $454 \mathrm{~nm}$. The incremental band gap energy values $\left(E_{\mathrm{g}}\right)$ in the sequence of $\mathbf{1}$ (original), $\mathrm{LH}_{5}$, and $\mathbf{1}$ (ground) in UV/Vis diffuse reflect spectra faultlessly fitted the hypsochromic shift fluorescence (Fig. 3D). Because of the stability of $\mathrm{Zn}^{2+}$ to oxidation-reduction, the solid-state luminescence properties of $\mathbf{1}$ was possibly attributed to intraligand centered transition $\left({ }^{1} \mathrm{ILCT}\right)^{47}$ with no ${ }^{1} \mathrm{MLCT} /{ }^{1} \mathrm{LMCT}$ which have been confirmed by the frontier orbital electron density isosurfaces of $\mathrm{LH}_{5}$ in DFT calculations (Fig. 7). The steady-state luminescent property of $\mathbf{1}$ (NMP) was also investigated (Fig. 3C). Intense fluorescence of $\mathbf{1}$ (NMP) appeared with emission maxima of $440 \mathrm{~nm}$. The strong and stable emission made 1 (NMP) sensor of choice for luminescent sensing of pesticides. The CIE plots of $\mathrm{LH}_{5}(0.1718,0.2521), 1$ (original) (0.1661, 0.2431), 1 (ground) (0.1618, 0.1684), and 1 (NMP) (0.1560, $0.1204)$ described the change tendency of luminescence (Fig. 3E). The quantum yields of $\mathbf{1}$ (original), $\mathbf{1}$ (ground), $\mathbf{1}$ (NMP) were determined to be $0.85,0.84$, and 0.77 , respectively.

\section{Luminescent stability of suspension sensor}

Before the detection of pesticides, the luminescent stability of $\mathbf{1}$ (NMP) has been investigated (Fig. 4A). Without ultrasonic

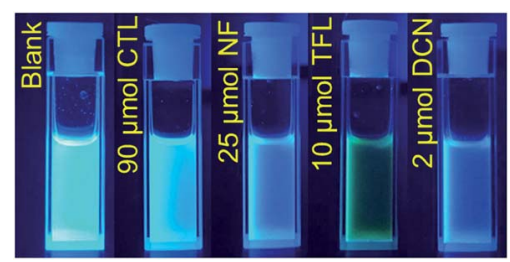

Fig. 5 Fluorescence variation of 1 (NMP) with trace addition of pesticides under $365 \mathrm{~nm}$ UV light. 
treatment, the fluorescence of $\mathbf{1}$ (NMP) weakened at a high rate of speed in the stabilization of $750 \mathrm{~s}$. And then the fluorescence weakened to less than $20 \%$ of original intensity which could hardly be observed after stabilization beyond 1500 s. By contrast, the fluorescence of $\mathbf{1}$ (NMP) with ultrasonic treatment remained above $80 \%$ of original intensity after stabilization of $2000 \mathrm{~s}$. The results confirmed that the luminescence stability of 1 (NMP) could be effectively improved by ultrasonic treatment. The particle size in suspension sensor of $\mathbf{1}$ (NMP) distributed in the range of 1000-2000 $\mathrm{nm}$ indicating the homogeneity of fine powder 1 (ground) and fine grinding manipulation (Fig. 4B).

\section{Luminescent sensing of pesticides with suspension sensor}

The luminescent sensing performances of $\mathbf{1}$ (NMP) to CTL, NF, TFL, and DCN were investigated by the gradual addition of solutions of pesticides. The sapphirine fluorescence of 1 (NMP) was observed and then rapidly quenched with trace addition of pesticide solutions. And the responses of fluorescence quenching could be readily identified with naked-eye observation with low-concentration addition of CTL $(90 \mu \mathrm{mol})$, NF $(25$ $\mu \mathrm{mol})$, TFL (10 $\mu \mathrm{mol})$, and DCN ( $2 \mu \mathrm{mol})$, respectively (Fig. 5).

The concentration-dependent fluorescence responses and corresponding fluorescence variation photographs of 1 (NMP) to DCN were exhibited in Fig. 6. 1 (NMP) demonstrated strong fluorescent emission with an intensity of 250 a.u. The emission intensity was reduced by the gradual addition of DCN. Notably, the fluorescence was quenched in seconds when DCN was added in 1 (NMP). The phenomena are promising for the effective "real-time" detection, that is to say, sensing of pesticides. The QE increased intensively in the low concentration range of $0-0.35 \mu \mathrm{mol}$ and leveled off in the high concentration

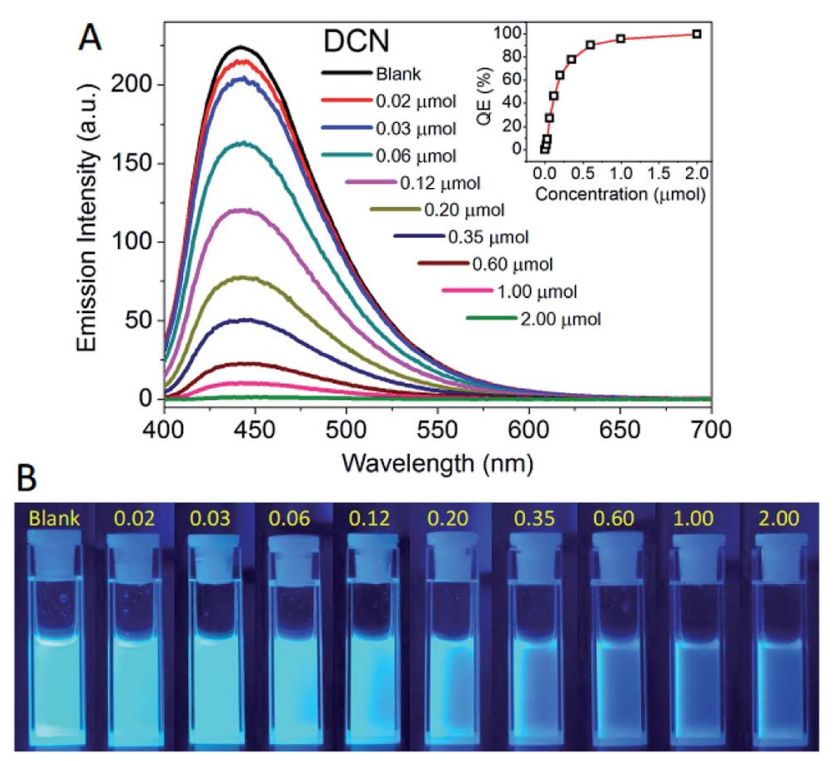

Fig. 6 (A) Concentration-dependent fluorescence responses of 1 (NMP) with different concentrations of DCN $\left(\lambda_{\text {ex }}=365 \mathrm{~nm}\right)$ inset: luminescent quenching efficiency ( $Q E)$ versus addition concentration of DCN. (B) Fluorescence variations of 1 (NMP) with step-by-step addition of DCN ( $\mu \mathrm{mol}$ ) under $365 \mathrm{~nm}$ UV light. range of $0.35-2.00 \mu \mathrm{mol}$ to achieve almost fully quenching. Similarly, the fluorescence of 1 (NMP) was also quenched by CTL, NF, and TFL (Fig. S6-S8, ESI $\dagger$ ). Upon more attention of the fluorescent spectra, it was found that the emission maximum of 1 (NMP) showed a unique bathochromic shift of $43 \mathrm{~nm}$ with the addition of TFL as compared with the emission maximum of blank (Fig. S8†). The phenomenon of emission maximum shift of 1 (NMP) to TFL could be caused by the strengthening of the hydrogen bonding between TFL and the excited-state of $\mathbf{1}$, which have rarely been reported in MOFs. ${ }^{48} 1$ (NMP) can be employed as a case study for the distinction of TFL with other pesticides by the shift of emission maxima.

\section{Mechanisms for luminescent sensing of pesticides}

The nitryl and cyano groups are typical electron-withdrawing substituents in the molecular architectures of pesticides. The origin of pesticide sensing should be assigned to the photoinduced electron transfer (PET) ${ }^{\mathbf{4 9}}$ and the fluorescence resonance energy transfer (FRET) ${ }^{33}$ from MOF to the pesticides. In general, the LUMOs of pesticides with nitryl and cyano groups are $\pi^{*}$ type orbitals with low energy levels. It can drive the PET process from MOF to the pesticide, which leads to fluorescence response and quenching if the LUMO energy level of the pesticide is close to or below that of the intraligand. The energy levels for HOMOs and LUMOs of $\mathrm{LH}_{5}$ and pesticides were calculated by density functional theory at B3LYP level with 6$31 \mathrm{G}^{* *}$ basis $\operatorname{set}^{\mathbf{5 0 , 5 1}}$ (Fig. 7). Compared to the LUMO energy levels of CTL $(-3.02 \mathrm{eV})$, NF $(-2.34 \mathrm{eV})$, TFL $(-2.96 \mathrm{eV})$, and DCN $(-2.41 \mathrm{eV})$, the higher LUMO energy level $(-2.33 \mathrm{eV})$ of the rich electronic $\mathrm{LH}_{5}$ could spontaneously facilitate the PET process between 1 and pesticide molecules.

The FRET mechanism is generated between the frameworks of 1 and pesticide molecules. The overlap between the UV/Vis spectra of pesticides and the emission spectrum of 1 (NMP) was applied to express the probability of FRET. As shown in Fig. 8, the spectral overlaps existed between 1 (NMP) and the pesticides confirming the FRET mechanism (Fig. 8). Thus, it can doubtlessly be indicated that the luminescent sensing mechanisms of 1 to CTL, NF, TFL, and DCN is assigned to the synergistic effect of the PET process and the FRET mechanism.

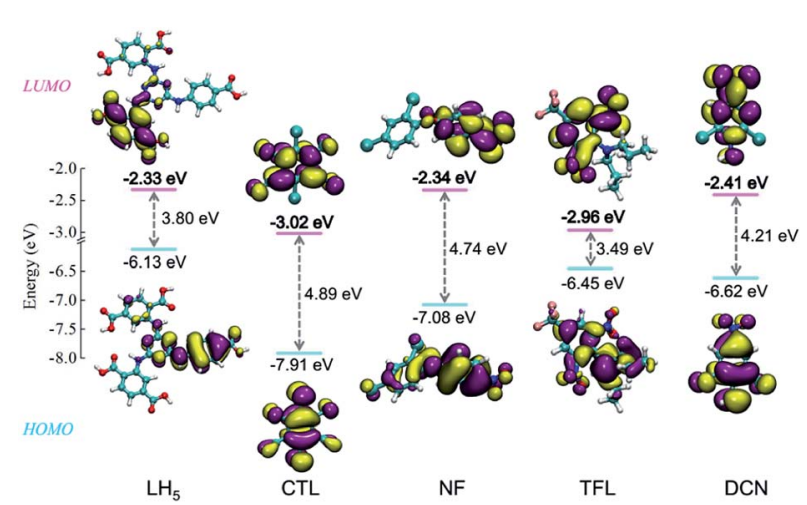

Fig. 7 Electron density isosurfaces (0.02 a.u.) and energy levels of HOMOs and LUMOs for $\mathrm{LH}_{5}$ and pesticides. 


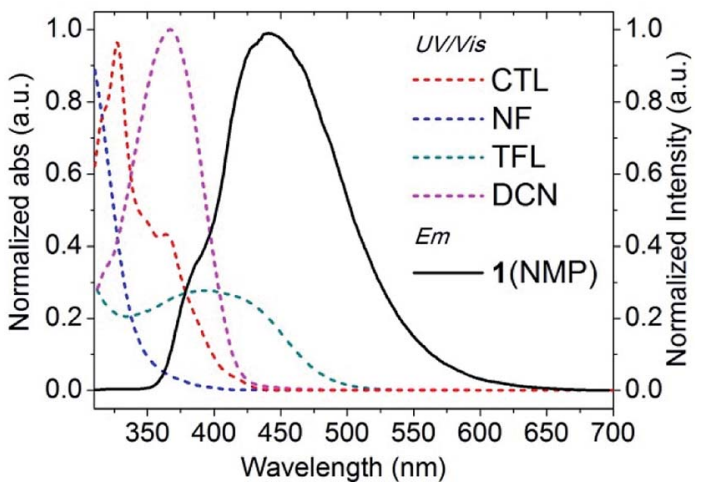

Fig. 8 Normalized spectral overlaps of the pesticides and 1 (NMP).

\section{Sensing efficiency of suspension sensor to pesticides}

The luminescent quenching process between 1 (NMP) and pesticides in Fig. 6 and S6-S8 (ESI $\dagger$ ) were fitted by the SternVolmer relationship ${ }^{52}$ (eqn. S1, ESI $\dagger$ ), and the fitting data were showed in Table S2 (ESI $\dagger$ ). Compared with CTL, the SternVolmer plots (SVPs) of NF, TFL, and DCN were nonlinear and demonstrated that higher concentrations lead to higher sensing efficiency (Fig. 9). The quenching constants $\left(K_{\mathrm{SV}}\right)$ of CTL, NF, TFL, and DCN were $0.163 \mu \mathrm{mol}^{-1}, 0.574 \mu \mathrm{mol}^{-1}, 6.072 \mu \mathrm{mol}^{-1}$, and $11.194 \mu \mathrm{mol}^{-1}$, respectively, with the order of DCN $>$ TFL $>$ NF $>$ CTL. The limit of detections (LODs) of 1 (NMP) to CTL, NF, TFL, and DCN were $201.01 \mathrm{ppm}, 57.08 \mathrm{ppm}, 5.40 \mathrm{ppm}$, and $2.93 \mathrm{ppm}$, which were calculated by $K_{\mathrm{SV}}(\mathrm{ESI} \dagger) .1$ (NMP) demonstrated the highest luminescent detection efficiency to DCN and the lowest LOD than other pesticides. The $K_{\mathrm{SV}}$ of 1 (NMP) to DCN was $1.84,19.50$, and 68.67 -fold higher than that of TFL, NF, and CTL, respectively, which established potential selectivity for sensing of DCN. Then the luminescent photographs and the emission intensities of $\mathbf{1}$ (NMP) in the presence of individual pesticides of CTL, NF, TFL and that together with the addition of DCN were recorded (Fig. 10). The fluorescent variation could be distinguished with naked eyes (Fig. 10A), and the emission intensity was significantly quenched when adding DCN into 1 (NMP) containing other pesticides (Fig. 10B). The

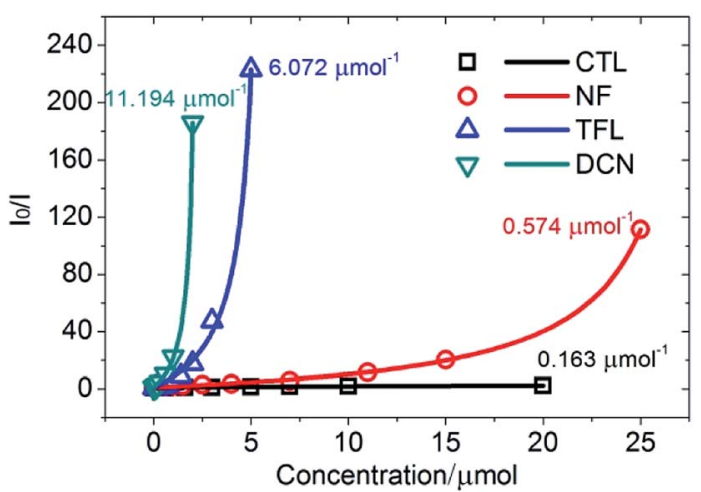

Fig. 9 Stern-Volmer plots of 1 (NMP) for luminescent sensing of pesticides $C T L, N F$, TFL, and DCN.
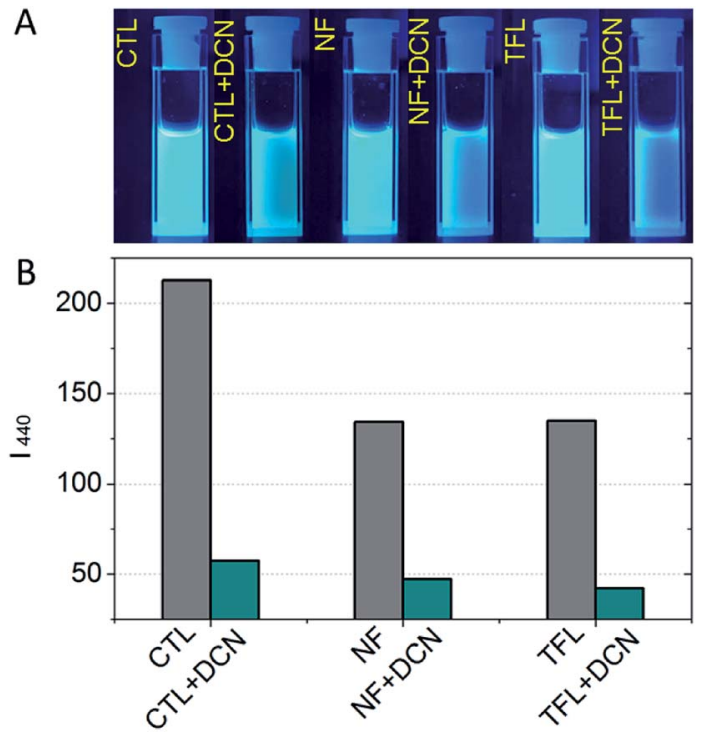

Fig. 10 (A) Fluorescence variations of 1 (NMP) with $0.4 \mu \mathrm{mol}$ pesticides before and after adding $0.4 \mu \mathrm{mol}$ DCN under $365 \mathrm{~nm}$ UV light and (B) the corresponding emission intensity histograms of 1 (NMP).

results confirmed that $\mathbf{1}$ (NMP) could be a highly selective sensor for DCN.

\section{Luminescent sensing of pesticides with film sensor}

The portability, rapid response, and selectivity of luminescent pesticide sensing have received much attention on the viewpoint of practical application. The alumina plate was employed for the preparation of luminescent film sensor which has advantages of low-cost, chemical inertness, and easy to adhesion by MOF. With the ultrasonic treatment in 5 minutes, 1 (NMP) was painted on the alumina plate $(2.5 \mathrm{~cm} \times 2.0 \mathrm{~cm})$ and dried at $85{ }^{\circ} \mathrm{C}$ for 4 hours to remove NMP. Then the MOF based luminescent film sensor 1 (film) was obtained, which presented neutral blue emission under $365 \mathrm{~nm}$ irradiation (Fig. 11). The superposed dripping of pesticide solutions (0.01 M in NMP, 100 $\mu \mathrm{L}$ ) of CTL, NF, and TFL onto 1 (film) led to no obvious change of fluorescence. And it could be seen clearly with naked eyes

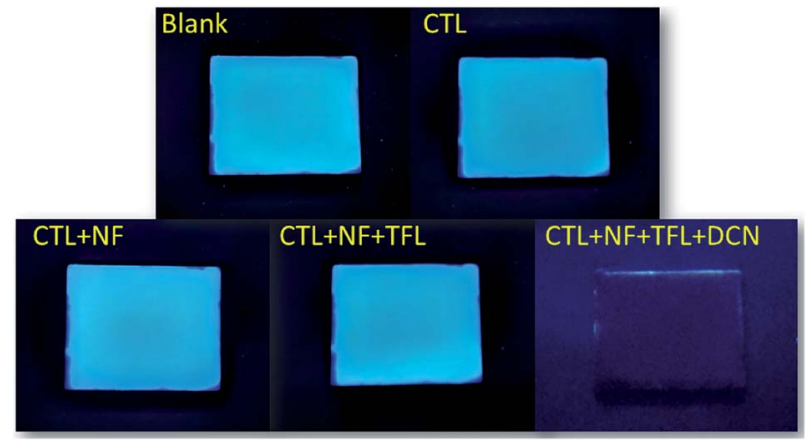

Fig. 11 Fluorescence quenching responses of 1 (film) with superposed dripping of solutions (0.01 M in NMP, $100 \mu \mathrm{L}$ ) of CTL, NF, TFL, and DCN under 365 nm UV light. 
Table 2 Comparison of MOF-based DCN sensors

\begin{tabular}{lllll}
\hline DCN sensors & Solvent & LOD $(\mathrm{ppm})$ & Selective sensing & Selective visualization film sensor \\
\hline Ref. 40 & $\mathrm{CH}_{2} \mathrm{Cl}_{2}$ & 0.13 & $\overline{-}$ & - \\
This work & $\mathrm{NMP}$ & 2.93 & $\checkmark$ & $\checkmark$
\end{tabular}

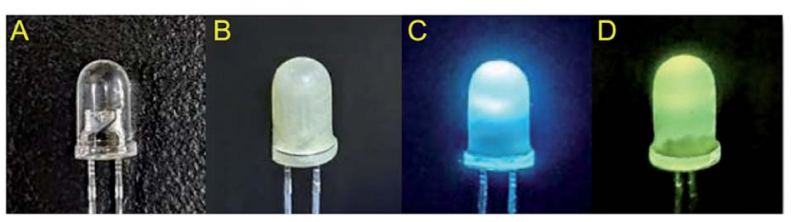

Fig. 12 (A) The commercially available ultraviolet LED. The (B) offstate and (C) on-state luminescent vapor sensor 1 (LED) (D) which has absorbed the vapor of TFL.

that the fluorescence of $\mathbf{1}$ (film) was quenched immediately by further dripping of DCN solution ( $0.01 \mathrm{M}$ in NMP, $100 \mu \mathrm{L}$ ) onto 1 (film) in the presence of CTL, NF, and TFL. The results illustrate that the film sensor $\mathbf{1}$ (film) is fit for selective visualization of trace analysis of DCN. Compared with the research of ref. 40, this work demonstrated a detailed study of selective sensing and visualization of DCN (Table 2).

\section{Luminescent vapor sensing of TFL}

As a practical application of vapor sensing, 1 (ground) was immobilized in a thin film of ethyl cellulose (EC) which was coated on a commercially available ultraviolet LED (Fig. 12A) to construct the luminescent vapor sensing device namely $\mathbf{1}$ (LED) (Fig. 12B). TFL possesses the preponderance of high saturated vapor pressure in comparison with CTL, NF, and DCN. Hence, the luminescent vapor sensing of TFL was implemented. 1 (LED) exhibited neutral blue emission at the applied voltage of $3 \mathrm{~V}$ in the air atmosphere (Fig. 12C). Then $\mathbf{1}$ (LED) was placed in a closed container with solid-state TFL at $60{ }^{\circ} \mathrm{C}$ for 2 minutes. With the same applied voltage, the neutral blue emission of 1 (LED) turned into bright kelly (Fig. 12D) which was consistent with the bathochromic shift of emission maximum of 1 (NMP) in Fig. S8 (ESI $\dagger$ ). The results demonstrated the excellent sensitivity and potential application for the vapor sensing of pesticides.

\section{Conclusions}

In conclusion, a 3D ABW-type Z-MOF 1 was applied for luminescent sensing of pesticides including TFL, CTL, NF, and DCN. With the synergistic effect of the PET process and the FRET mechanism, the suspension sensor 1 (NMP) exhibited high sensing performances to TFL, CTL, NF, and high selectivity to DCN. The $K_{\mathrm{SV}}$ of 1 (NMP) to CTL, NF, TFL, and DCN were 0.163 $\mu \mathrm{mol}^{-1}, 0.574 \mu \mathrm{mol}^{-1}, 6.072 \mu \mathrm{mol}^{-1}$, and $11.194 \mu \mathrm{mol}^{-1}$, respectively, with LODs of $201.01 \mathrm{ppm}, 57.08 \mathrm{ppm}, 5.40 \mathrm{ppm}$, and $2.93 \mathrm{ppm}$. The low-cost luminescent film sensor $\mathbf{1}$ (film) illustrated the selective visualization sensing of DCN.
Furthermore, the luminescent vapor sensing device 1 (LED) demonstrated a potential application for the vapor sensing of pesticides. The current work creates a bran-new prospect on MOF based luminescent sensors for highly selective sensing and visualization of pesticides.

\section{Conflicts of interest}

There are no conflicts to declare.

\section{Acknowledgements}

The work was funded by the National Natural Science Foundation of China (21671092, 21803042), the Liaoning Revitalization Talents Program (XLYC1802057), the Education Department of Liaoning Province (L2019039, L2017LQN007), the Talent Scientific Research Funds of Liaoning Shihua University (2017XJJ-001, 2016XJJ-099), the Natural Science Basic Research Program of Shaanxi (2019JQ-067), and the 64th China Postdoctoral Science Foundation Funded Project (2018M643706).

\section{Notes and references}

1 Y. Zhou, B. Yan and F. Lei, Chem. Commun., 2014, 50, 15235.

2 J. Chen, Y. Huang, P. Kannan, L. Zhang, Z. Lin, J. Zhang,

T. Chen and L. Guo, Anal. Chem., 2016, 88, 2149.

3 A. Evenset, I. G. Hallanger, M. Tessmann, N. Warner, A. Ruus, K. Borga, G. W. Gabrielsen, G. Christensen and P. E. Renaud, Sci. Total Environ., 2016, 542, 108.

4 K. H. Kim, E. Kabir and S. A. Jahan, Sci. Total Environ., 2017, $575,525$.

5 H. Su, Y. Lin, Z. Wang, Y. L. Wong, X. Chen and T. W. Chan, J. Chromatogr. A, 2016, 1466, 21.

6 S. Li, X. Zhang and Y. Huang, J. Hazard. Mater., 2017, 321, 711.

7 A. K. Malik and W. Faubel, Crit. Rev. Anal. Chem., 2001, 31, 223.

8 P. L. Chang, M. M. Hsieh and T. C. Chiu, Int. J. Environ. Res. Public Health, 2016, 13, 409.

9 P. Kumar, K. H. Kim and A. Deep, Biosens. Bioelectron., 2015, 70, 469.

10 Y. Chen, S. Lopez, D. G. Hayward, H. Y. Park, J. W. Wong, S. S. Kim, J. Wan, R. M. Reddy, D. J. Quinn and D. Steiniger, J. Agric. Food Chem., 2016, 64, 6125.

11 Y. H. Zheng, T. C. Hua, D. W. Sun, J. J. Xiao, F. Xu and F. F. Wang, J. Food Eng., 2006, 74, 24.

12 D. K. Singha, P. Majee, S. K. Mondal and P. Mahata, ChemistrySelect, 2017, 2, 5760. 
13 F. Y. Yi, D. Chen, M. K. Wu, L. Han and H. L. Jiang, ChemPlusChem, 2016, 81, 675.

14 N. Xu, Q. Zhang, B. Hou, Q. Cheng and G. Zhang, Inorg. Chem., 2018, 57, 13330.

15 P. Horcajada, R. Gref, T. Baati, P. K. Allan, G. Maurin, P. Couvreur, G. Ferey, R. E. Morris and C. Serre, Chem. Rev., 2012, 112, 1232.

16 C. He, D. Liu and W. Lin, Chem. Rev., 2015, 115, 11079.

17 Y. M. Ying, C. L. Tao, M. Yu, Y. Xiong, C. R. Guo, X. G. Liu and Z. Zhao, J. Mater. Chem. C, 2019, 7, 8383.

18 M. Zhao, Y. Huang, Y. Peng, Z. Huang, Q. Ma and H. Zhang, Chem. Soc. Rev., 2018, 47, 6267.

19 X. J. Che, S. L. Hou, Y. Shi, G. L. Yang, Y. L. Hou and B. Zhao, Dalton Trans., 2019, 48, 3453.

20 B. Yan, J. Mater. Chem. C, 2019, 7, 8155.

21 X. X. Wu, H. R. Fu, M. L. Han, Z. Zhou and L. F. Ma, Cryst. Growth Des., 2017, 17, 6041.

22 Z. Zhou, M. L. Han, H. R. Fu, L. F. Ma, F. Luo and D. S. Li, Dalton Trans., 2018, 47, 5359.

23 A. Yousaf, A. M. Arif, N. Xu, J. Zhou, C. Y. Sun, X. L. Wang and Z. M. Su, J. Mater. Chem. C, 2019, 7, 8861.

24 B. H. Wang and B. Yan, CrystEngComm, 2019, 21, 1186.

25 L. Di, S. Q. Liu, Y. Xie, J. Zhu, Y. J. Sun, J. Ni and J. J. Zhang, Inorg. Chim. Acta, 2015, 438, 153.

26 L. Sun, M. G. Campbell and M. Dincă, Angew. Chem., Int. Ed., 2016, 55, 3566.

27 P. Kumar, A. K. Paul and A. Deep, Anal. Methods, 2014, 6, 4095.

28 X. J. Liu, Y. H. Zhang, Z. Chang, A. L. Li, D. Tian, Z. Q. Yao, Y. Y. Jia and X. H. Bu, Inorg. Chem., 2016, 55, 7326.

29 B. Liu, J. Mater. Chem., 2012, 22, 10094.

30 J. M. Taylor, K. W. Dawson and G. K. H. Shimizu, J. Am. Chem. Soc., 2013, 135, 1193.

31 A. Deep, S. K. Bhardwaj, A. K. Paul, K. H. Kim and P. Kumar, Biosens. Bioelectron., 2015, 65, 226.

32 L. Di, J. J. Zhang, S. Q. Liu, J. Ni, H. Zhou and Y. J. Sun, Cryst. Growth Des., 2016, 16, 4539.

33 Y. Dai, H. Zhou, X. D. Song, J. J. Zhang, C. Hao, L. Di, Y. X. Wang, J. Ni and H. L. Wang, CrystEngComm, 2017, 19, 2786.

34 Q. He, J. Huang, X. Yang, X. Yan, J. He, S. Li and J. Jiang, Food Control, 2016, 64, 70.

35 X. Yang, B. Bennett and R. C. Holz, J. Biol. Chem., 2019, 294, 13411.

36 S. Hirako, H. Tsuda, F. Ito, Y. Okazaki, T. Hirayama, H. Nagasawa, T. Nakano, K. Imai, T. Kotani, F. Kikkawa and S. Toyokuni, J. Clin. Biochem. Nutr., 2017, 61, 176.

37 R. Grover, J. D. Wolt, A. J. Cessna and H. B. Schiefer, in Reviews of Environmental Contamination and Toxicology:
Continuation of Residue Reviews, ed. G. W. Ware, Springer New York, New York, NY, 1997.

38 T. C. C. Fernandes, D. E. C. Mazzeo and M. A. MarinMorales, Pestic. Biochem. Physiol., 2007, 88, 252.

39 S. Mosleh and M. R. Rahimi, Ultrason. Sonochem., 2017, 35, 449.

40 C. L. Tao, B. Chen, X. G. Liu, L. J. Zhou, X. L. Zhu, J. Cao, Z. G. Gu, Z. Zhao, L. Shen and B. Z. Tang, Chem. Commun., 2017, 53, 9975.

41 L. Di, Y. Xing, X. Wang, D. Zheng, Y. Yang and F. Li, RSC Adv., 2018, 8, 41040.

42 Y. Xing, C. Qiao, X. Li, C. Li, H. Wang, F. Li, L. Di and Z. Yang, RSC Adv., 2019, 9, 15370.

43 W. Lu, Z. Wei, Z. Y. Gu, T. F. Liu, J. Park, J. Park, J. Tian, M. Zhang, Q. Zhang, T. Gentle III, M. Bosch and H. C. Zhou, Chem. Soc. Rev., 2014, 43, 5561.

44 T. Lee, M. H. Tsai and H. L. Lee, Cryst. Growth Des., 2012, 12, 3181.

45 L. Ma, X. Feng, S. Wang and B. Wang, Mater. Chem. Front., 2017, 1, 2474.

46 X. X. Wang, X. Q. Wang, X. Y. Niu and T. P. Hu, CrystEngComm, 2016, 18, 7471.

47 L. P. Zhang, J. F. Ma, J. Yang, Y. Y. Pang and J. C. Ma, Inorg. Chem., 2010, 49, 1535.

48 G. J. Zhao and K. L. Han, Acc. Chem. Res., 2012, 45, 404.

49 K. Vikrant, D. C. W. Tsang, N. Raza, B. S. Giri, D. Kukkar and K. H. Kim, ACS Appl. Mater. Interfaces, 2018, 10, 8797.

50 M. J. Frisch, G. W. Trucks, H. B. Schlegel, G. E. Scuseria, M. A. Robb, J. R. Cheeseman, G. Scalmani, V. Barone, B. Mennucci, G. A. Petersson, H. Nakatsuji, M. Caricato, X. Li, H. P. Hratchian, A. F. Izmaylov, J. Bloino, G. Zheng, J. L. Sonnenberg, M. Hada, M. Ehara, K. Toyota, R. Fukuda, J. Hasegawa, M. Ishida, T. Nakajima, Y. Honda, O. Kitao, H. Nakai, T. Vreven, J. A. Montgomery, J. E. Peralta, F. Ogliaro, M. Bearpark, J. J. Heyd, E. Brothers, K. N. Kudin, V. N. Staroverov, R. Kobayashi, J. Normand, K. Raghavachari, A. Rendell, J. C. Burant, S. S. Iyengar, J. Tomasi, M. Cossi, N. Rega, J. M. Millam, M. Klene, J. E. Knox, J. B. Cross, V. Bakken, C. Adamo, J. Jaramillo, R. Gomperts, R. E. Stratmann, O. Yazyev, A. J. Austin, R. Cammi, C. Pomelli, J. W. Ochterski, R. L. Martin, K. Morokuma, V. G. Zakrzewski, G. A. Voth, P. Salvador, J. J. Dannenberg, S. Dapprich, A. D. Daniels, O. Farkas, J. B. Foresman, J. V. Ortiz, J. Cioslowski and D. J. Fox, Gaussian 16, Revision A.03, Gaussian, Inc., Wallingford, CT, 2016.

51 W. Humphrey, A. Dalke and K. Schulten, J. Mol. Graphics, 1996, 14, 33.

52 X. D. Wang and O. S. Wolfbeis, Chem. Soc. Rev., 2014, 43, 3666. 